\title{
MULTI-INSTRUMENTAL IDENTIFICATION OF ORPIMENT IN ARCHAEOLOGICAL MORTUARY CONTEXTS
}

\author{
JUAN PABLO OGALDE ${ }^{*}$, CRISTIAN O. SALAS ${ }^{2}$, NELSON LARA ${ }^{1}$, PATRICIO LEYTON ${ }^{3}$, CAROLINA PAIPA ${ }^{4}$, \\ MARCELO CAMPOS-VALLETTE ${ }^{5}$ and BERNARDO ARRIAZA ${ }^{6}$
}

'Departamento de Química, Facultad de Ciencias, Universidad de Tarapacá. Av. General Velásquez 1775, Arica, Chile.

${ }^{2}$ Departamento de Química Orgánica, Facultad de Química, Pontificia Universidad Católica, Santiago, Chile.

${ }^{3}$ Instituto de Química, Pontificia Universidad Católica de Valparaiso, Valparaíso, Chile.

${ }^{4}$ Departamento de Ciencias Químicas, Facultad de Ciencias Exactas, Universidad Andrés Bello, Viña del Mar, Chile.

${ }^{5}$ Departamento de Química, Facultad de Ciencias, Universidad de Chile.

${ }^{6}$ Instituto de Alta Investigación, Universidad de Tarapacá, Arica, Chile.

\begin{abstract}
This paper reports on an unknown yellowish mineral compound found in an archaeological context from Chorrillos cemetery (Calama, Chile) dating to the Early Formative period (800 - 200 B.C.). We used optic microscopy, SEM, EDX, ${ }^{1} \mathrm{H}-\mathrm{RMN},{ }^{13} \mathrm{C}-\mathrm{RMN}$, and infrared (IR) and Raman spectroscopy to tease out the chemical and molecular composition of the sample. The microscopic images show amorphous yellowish granulates with heterogeneous chemical surfaces. ${ }^{1} \mathrm{H}$ RMN and ${ }^{13} \mathrm{C}$-RMN negative results show that the sample is free of organic matter. The SEM and EDX indicate the presence of arsenic and sulfur in the sample. The IR and Raman analyses suggest the presence of orpiment which is a toxic yellow arsenic sulfide mineral.
\end{abstract}

Keywords: Pigments, Raman spectroscopy, SEM-EDX, Chorrillos, Northern Chile.

\section{INTRODUCTION}

Instrumental analyses of pigment usage have a significant value to play in many disciplines, such as natural resources, prehistoric artistic expression, archaeology and art history. It is a useful tool to identify and characterize pigments, elemental chemical composition, toxicity, usage, etc. Microsampling and non-destructive techniques are also important variables to consider when dealing with cultural patrimony and unique objects while pursuing chemical characterization and analyses of ancient samples ${ }^{1-8}$.

This paper reports on analyses made on archaeological colored sediment from an ancient funerary site in Chorrillos, Calama city, in northern Chile. This archaeological sample is an unknown yellow pigment (Figure 1a). The pigment sample was found in a mollusk shell that was part of the grave goods associated with a female individual (ca. 25 - 30 years old) dating to the Early Formative period (800-200 B.C.). Yellow arsenic sulfide minerals occur naturally and many studies have reported its use by ancient cultures ${ }^{1,9-11}$. Here we show the first study of an archaeological pigment from Calama and we discuss structural analyses that were undertaken to carry out the identification of orpiment.

\section{PRELIMINARY CONSIDERATIONS}

In the 1950s it was thought that although the structure of orpiment $\left(\mathrm{As}_{2} \mathrm{~S}_{3}\right)$, is a common monoclinic crystal system of an arsenic sulfide mineral $(\mathrm{P} 2 / \mathrm{c}$, $\mathrm{a}=4.256 \AA ; \mathrm{b}=9.577 \AA ; \mathrm{c}=12.19 \AA$ and $\beta=109.75^{\circ}$ ), it seemed to have little similarity with the orange-red arsenic sulfide mineral realgar $\left(\alpha-\mathrm{As}_{4} \mathrm{~S}_{4}\right)^{12-14}$. In the 1970s it was shown that both structures were in fact built from the same structural units, but upon different principles ${ }^{3}$. Thereupon, realgar was thought to light-degrade to orpiment and arsenic oxide $\left(\mathrm{As}_{2} \mathrm{O}_{3}\right.$, arsenolite), which is consistent with the color change from red/orange to orange/yellow, however this is not the case $\mathrm{e}^{12-15}$.

Today we know that pararealgar, another arsenic sulfide mineral $\left(\beta-\mathrm{As}_{4} \mathrm{~S}_{4}\right)$ is an intermediate yellow pigment in the fading of realgar to arsenolite. Thus, under the influence of light, particularly between 550 and $610 \mathrm{~nm}$, the orangered realgar $\left(\alpha-\mathrm{As}_{\mathrm{s}} \mathrm{S}_{4}\right)$ can change its structure to an orange product $(\alpha$-realgar) and then to yellow pararealgar $\left(\beta-\mathrm{As}_{4} \mathrm{~S}_{4}\right)$. Then, pararealgar has been demonstrated to convert to arsenolite by photochemical reaction ${ }^{15-16}$. Arsenolite is also the product of orpiment fading, thus the final appearance of both realgar and orpiment pigments are colorless or white. However, orpiment is not part of realgar degradation ${ }^{16}$. Subsequent research has shown that when exposed to light realgar changes to pararealgar, not to orpiment ${ }^{16-20}$. The formation of orpiment by the deterioration of realgar is not thermodynamically favored ${ }^{14-20}$.

Orpiment and pararealgar are yellow, while realgar is an orange to red mineral. All these pigments have different chemical signatures or vibrational bands under structural analyses such as Raman or IR spectroscopy. But, to the untrained eye, several factors complicate visual recognition of the various phases of realgar, pararealgar and orpiment. Thus, the study of these colored minerals may require one or more analytical techniques for proper identification.

\section{MATERIAL AND METHODS}

\section{Light microscopy and SEM-EDX analyses}

About $3 \mathrm{mg}$ of selected pigment were analysed using stereomicroscopy (Olympus SZX-7) and EVO LS Scanning Electron Microscopy (SEM). SEM Images were captured at $100 \mathrm{x}$ and $600 \mathrm{x}$ with secondary and backscattered electron detectors. The sample was also analysed using an Oxford EDX detector $(8.5 \mathrm{WD}$ and $450 \mathrm{kV})$. The spectrometry data was viewed and interpreted with INCA software. The analysis was made at the Bioarchaeology Lab, Instituto de Alta Investigación of the Universidad de Tarapacá.

\section{Infrared analyses}

The infrared spectra were measured on a Fourier Transform Infrared (FT-IR) Bruker Vector 22 spectrometer equipped with a DTGS (deuterated triglycine sulfate) detector. The spectral resolution was $4 \mathrm{~cm}^{-1}$, and 16 scans were performed. A pellet was prepared by mixing $1 \mathrm{mg}$ of the solid sample and $200 \mathrm{mg}$ of polyethylene. This analysis was made in the Facultad de Química Orgánica of the Pontificia Universidad Católica of Chile.

\section{Raman analyses}

About $50 \mathrm{mg}$ of solid sample was placed onto a microscopy slide and the Raman spectrum was recorded using a Renishaw Raman Microscope System RM1000 equipped with a diode laser providing the $785 \mathrm{~nm}$ line, a Leica microscope, an electrically cooled CCD (charge coupled device) detector and a notch filter to eliminate elastic scattering. The spectrum was obtained using a $50 \mathrm{x}$ objective. The laser power output was $2.0 \mathrm{~mW}$, and the spectral resolution was $2 \mathrm{~cm}^{-1}$. This analysis was undertaken at the Facultad of Ciencias of the Universidad de Chile.

\section{${ }^{1} \mathrm{H}$ - and ${ }^{13} \mathrm{C}-\mathrm{RMN}$ analyses}

Nuclear magnetic resonance spectra were recorded on a Bruker WM-250 apparatus using $\mathrm{CDCl}_{3}$, DMSO or $\mathrm{D}_{2} \mathrm{O}$ organic solvents (around $10 \mathrm{mg}$ were suspended in $1 \mathrm{~mL}$ ) containing tetramethylsilane as an internal standard. This analysis was undertaken at the Facultad de Química Orgánica of the Pontificia Universidad Católica of Chile. 


\section{RESULTS AND DISCUSSION}

The light microscopy shows some crystal and fibers blended with yellow material (Figure 1a). The SEM images (using backscattered electrons) show that the granules are an amorphous solid material with a heterogeneous chemical surface (Figure 1b).

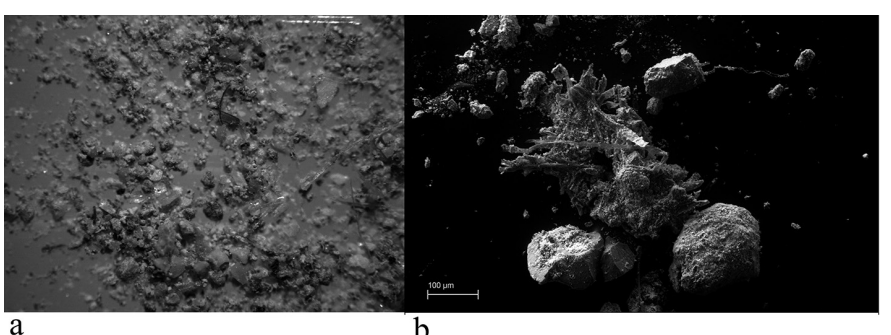

Figure 1. Archaeological sample (a) Optical microscopic image (32x) (b) Backscattered SEM image (1.24x) of a single granule.

In a preselected granule with SEM analyses, smooth areas were labelled in order to perform the elemental analyses (Figure 2a). Semi-quantitative results of EDX characterization on several of these granules show high arsenic and sulphur percentages in all analysed areas. Also, the elements oxygen (major peak) and silicon (fourth major peak) show significant percentages (Figure 2b). Thus, a vibrational spectral analysis was performed on the basis of previous band assignments and data reported to test for specific arsenic sulphides ${ }^{21-26}$.
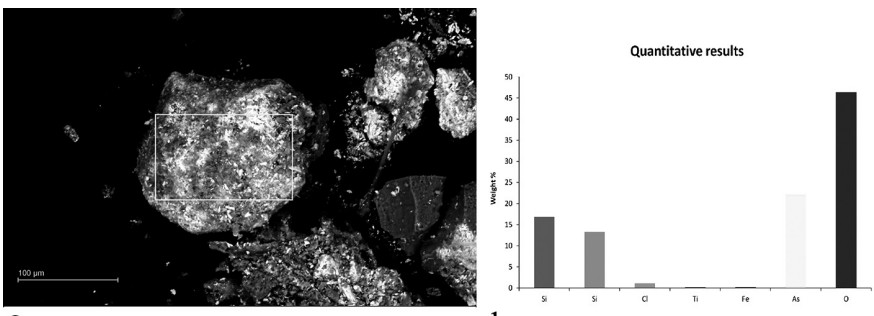

a

$\mathrm{b}$

Figure 2. a) Backscattered SEM image (616X) and b) chart of results with As (second major peak, 22.03\%) and S (fourth major peak, 13.27\%).

Theoretically, the IR spectra of orpiment and realgar have two distinct spectral regions where the strongest bands are present. The stretching vibrations are centered on $350 \mathrm{~cm}^{-1}$ in the first region ( 300 to $400 \mathrm{~cm}^{-1}$ ), with few bands of medium and weak intensity. The second region $\left(200\right.$ to $\left.300 \mathrm{~cm}^{-1}\right)$ shows bands due to S-As-S bending, centered around $250 \mathrm{~cm}^{-1} 12,21-26$. In the IR spectrum of the archaeological sample (Figure 3 ) we show the characteristic orpiment bands between 250 and $400 \mathrm{~cm}^{-1}$ due to the As-S stretching ${ }^{12,21-26}$.



Figure 3. Infrared spectra from archaeological yellow pigment.
We used Raman spectroscopy to corroborate the exact chemical nature of the pigment. The spectra were registered between 100 and $2000 \mathrm{~cm}^{-1}$. Figure 4 displays the Raman spectra in the 130 to $400 \mathrm{~cm}^{-1}$ spectral region. The unknown archaeological mineral displays the same spectral profile than orpiment reference sample according to library spectrum (R060105) from RRUFF $^{\mathrm{TM}}$ mineral database. In Figure $4 \mathrm{a}$ and $4 \mathrm{~b}$ the eight bands appear at the same frequencies with similar relative intensities, indicating that they are likely the same compound. Moreover, the archaeological sample and the orpiment reference (Figure $4 \mathrm{a}$ and $4 \mathrm{~b}$ ) are different from realgar and pararealgar spectra (Figure $4 \mathrm{c}$ and $4 \mathrm{~d}$ ). Thus, the yellow pigment is orpiment. A complete assignment of the bands obtained is shown in Table 1 according with previous data reported ${ }^{12,17-26}$.

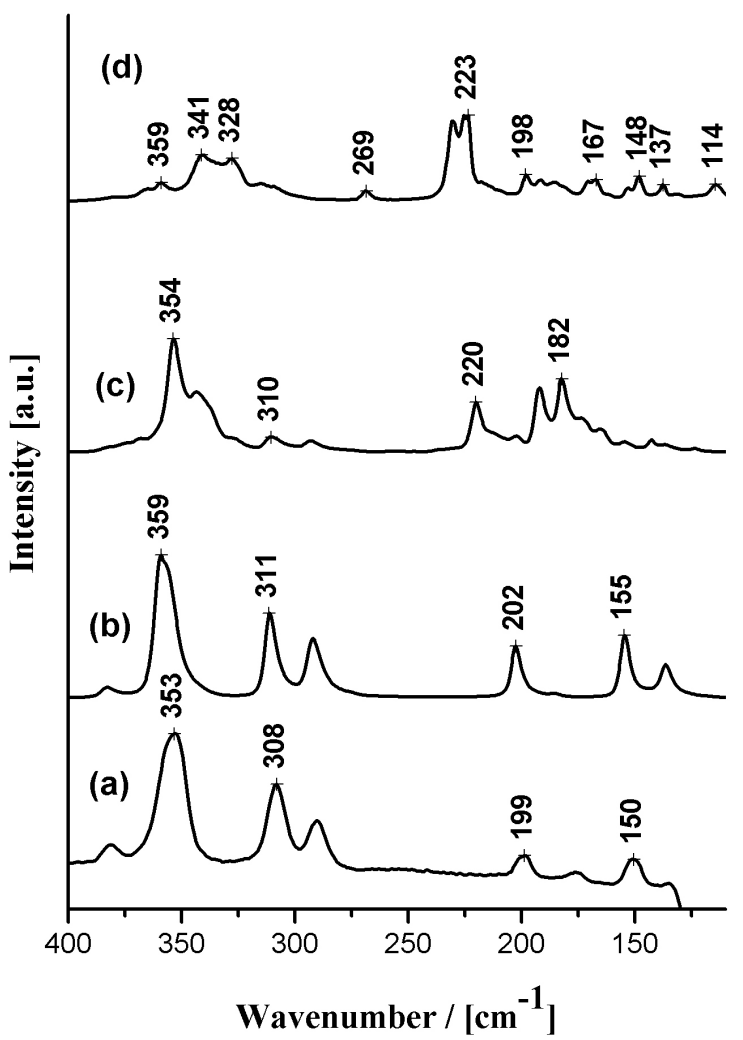

Figure 4. Raman spectra from archaeological yellow pigment and library standard: (a) Archeological sample, (b) Orpiment reference, (c) Realgar reference and (d) Pararealgar reference.

The identified archaeological orpiment sample, was dissolved in different deuterated organic solvents, such as, chloroform- $d$, acetone- $d$, dimethylsulfoxide- $d_{\text {and }}$ andeuterated water, with the goal to looking for organic compounds that could be present. However in the ${ }^{1} \mathrm{H}$ NMR and ${ }^{13} \mathrm{C}$ NMR spectra no signals belong to hydrogen or carbon atoms that would relate to an organic compound were found. This evidence indicates the absence of any organic compound in the pigment sample.

The archaeological orpiment is an arsenic sulphide, toxic to humans ${ }^{27}$. Therefore, it is interesting that people of Calama, during the Formative Period, were using this type of dangerous pigment as a funerary grave good. These analyses open the question of how this mineral was mined in ancient times. Sources of pigments such as arsenic sulphides in particular would be interesting to trace and of course their hidden dangers in ancient populations of northern Chile. Whether they were using this pigment for painting ornaments, ceramics, and body decorations or for medicinal purposes is a question to investigate in future studies. We know colourful pigments (manganese, iron) and funerary behaviour have been reported for the Chinchorro Culture and for rock art in northern Chile ${ }^{28-32}$. This new evidence suggests that ancient populations were familiar with several pigments that are beautiful but some dangerous to human health ${ }^{27-35}$. This study has been useful to identify raw material used by ancient Calama inhabitants. 
Table 1. Raman wavenumbers $\left(\mathrm{cm}^{-1}\right)$ of the archaeological yellow pigment.

\begin{tabular}{|c|c|c|}
\hline $\begin{array}{c}\text { Archaeological } \\
\text { sample }\end{array}$ & \multirow{2}{*}{$\begin{array}{l}\text { Vibrational } \\
\text { assignment }\end{array}$} & \multirow[t]{2}{*}{ Comments } \\
\hline $\operatorname{Raman}\left(\mathrm{cm}^{-1}\right)$ & & \\
\hline $381 \mathrm{w}$ & $v_{\mathrm{a}}(\mathrm{As}-\mathrm{S}-\mathrm{As})$ & $\begin{array}{c}\text { Asymmetric stretching of As-S- } \\
\text { As bridges }\end{array}$ \\
\hline 353 vs & $v_{\mathrm{a}} \mathrm{AsS}_{3 / 2}$ & Pyramids $\mathrm{AsS}_{3 / 2}$ \\
\hline $308 \mathrm{~s}$ & $v_{\mathrm{a}} \mathrm{AsS}_{3 / 2}$ & $\begin{array}{l}\text { Asymmetric stretching of } \\
\text { pyramids } \mathrm{AsS}_{3 / 2}\end{array}$ \\
\hline $290 \mathrm{~m}$ & $v_{\mathrm{s}} \mathrm{AsS}_{3 / 2}$ & $\begin{array}{c}\text { Symmetric stretching of } \\
\text { pyramids } \mathrm{AsS}_{3 / 2}\end{array}$ \\
\hline $199 \mathrm{w}$ & $v_{s}(\mathrm{As}-\mathrm{S}-\mathrm{As})$ & $\begin{array}{l}\text { Symmetric stretching of As-S- } \\
\text { As bridges }\end{array}$ \\
\hline $177 \mathrm{vw}$ & $\delta \mathrm{AsS}_{3 / 2}$ & Bending pyramids $\mathrm{AsS}_{3 / 2}$ \\
\hline $150 \mathrm{w}$ & $\delta$ (skel) & Skeletal deformation \\
\hline $131 \mathrm{~m}$ & $v_{4}$ & Bending pyramids $\mathrm{AsS}_{3 / 2}$ \\
\hline
\end{tabular}

Bands intensity: $\mathrm{w}=$ weak, $\mathrm{vs}=$ very strong, $\mathrm{s}=$ strong, $\mathrm{m}$ medium, $\mathrm{vw}$ $=$ very weak.

\section{CONCLUSIONS}

The multi-instrumental approach to study an unknown yellow archaeological pigment, suggest that is orpiment. It is interesting that during the Formative Period, the people of Calama were using this type of dangerous pigment as funerary grave goods. Future studies could focus on the sources of origin, extraction and management of this dangerous mineral. We suggest that it is important museum staff take necessary safety precautions, such as use of gloves, clean lab coats, and new dust masks when handling pigments, especially red pigment such as cinnabar or the yellow orpiment pigment analysed here.

\section{ACKNOWLEDGEMENTS}

With great appreciation to personnel and scholars of Depósito Arqueológico de Calama for their collaboration and permission to analyze the pigment sample ( $\mathrm{n}^{\circ}$ register A-74). We also thank Vicki Cassman for her comments and suggestions. Juan Pablo Ogalde acknowledges the support provided by the Convenio de Desempeño, Universidad de Tarapacá-MINEDUC and Programa de Doctorado en Ciencias mención Química at this University. M. CamposVallette acknowledges project Fondecyt 1110106 and P. Leyton thanks FONDEQUIP EQM-130170.

\section{REFERENCES}

1. L. Burgio, R. Clark, G. Martin, E. Pantos, and M. Roberts. A multidisciplinary approach to pigment analysis: king's yellow and dragon's blood from the Winsor and Newton pigment box at the Victoria and Albert Museum. Proceedings of the workshop on structural molecular archaeology, Ettore, Majorana Eentre, Erice, Sicily, 25-27 May 2002.

2. D. J. Kennett, S. Sakai, H. Neff, R. Gossett and D.O. Larson. J. Archaeol. Sci., 29, 443-455, (2002)

3. L.M. Di Stefano and R. Fuchs. Archaeol Anthropol Sci., 3, 229-244, (2011).

4. A. Kriznar, J. Höfler, A. Ruiz-Conde, and P.J. Sanchez-Soto. Bol. Soc. Esp. Ceram., 46(2), 76-85, (2007).

5. T. Aguayo, E. Clavijo, A. Villagrán, F. Espinosa, F. E. Sagüés and M. Campos-Vallette. J. Chil. Chem. Soc., 55(3), 347-351, (2010).

6. K. Strzalka, R. Szymanska and M. Suwalsky. J. Chil. Chem. Soc., 56(3), 808-811, (2011).

7. S. Nasir, T. B. Sarfaraz, K. M. Khan, A. Aleem and R. Parveen. J. Chil. Chem. Soc., 56(1), 559-565, (2011).

8. C. Vergara, D. Von Baer, I. Hermosín, A. Ruiz, M.A. Hitschfeld, N. Castillo and C. Mardones. J. Chil. Chem. Soc., 54(2), 194-197, (2009).

9. V.F. Muralhaa, L. Burgioa, and R.J. Clark. Spectrochim. Acta Part A 92, 21- 28, (2012).

10. D.A. Ciomartan and R.J.H. Clark. 1996. J. Braz. Chem. Soc., 7(6), 395402, (1996).
11. S. N. Gaidhani, A. Singh, C. E. Lagand, S. Kumari, G. S. Lavekar, M. M. Padhi and B. S. Sharma. J. Sci. \& Insdustrial Res., 70, 871-874, (2011).

12. R. Forneris. Am. Mineralogist, 54, 1062-1074, (1969).

13. N. Morimoto. Mineralogical J., 1(3), 160-169, (1954).

14. T. Ito N. Morimoto and R. Sandanaga. Acta Cryst., 5, 775-782, (1952).

15. V. Daniels and B. Leach. Studies in Conservation, 49, 73-84, (2004).

16. K. Trentelman, L. Stodulski, and M. Pavlosky. Chem., 68, 1755-1761, (1996).

17. P. Bonazzi, S. Menchetti and G Protesi. Am. Mineral, 80, 400-403, (1995).

18. D.L. Douglass, and C. Shing. Am. Min., 7, 1266-1274, (1992).

19. P. Bonazzi, S. Menchetti, G. Pratesi, M. Muniz-Miranda, and G. Sbrana. Am. Mineral., 81, 874-880, (1996).

20. P. Naumov, P. Makreski, and G. Jovanovski. Inorg. Chem., 46, 1062410631, (2007)

21. E. Kendix. Transmission and Reflection (ATR) Far-Infrared Spectroscopy Applied in the Analysis of Cultural Heritage Materials. PhD Thesis Università di Bologna, 2009.22. E. Kendix, S. Prati, E. Joseph, G. Sciutto, and R. MŠazzeo. Anal. Bioanalytical Chem., 394(4), 1023-1032, (2009).

23. S.T. Itoh, and T. Fujiwara. J. Non-Crystalline Solids, 51, 175-186, (1982).

24. M. Trajkovskal, B. Šoptrajanov, G. Jovanovski and T. Stafilov. J. Mol. Struc. 267, 191-196, (1992).

25. P. Colomban, A. Tournie, and L. Bellot-Gurlet. J. Raman Spec., 37, 841$852,(2006)$.

26. R. Soong and V.C. Farmer. 1978. Mineralogical magazine, 42, 277-281, (1978).

27. J.A. Buchanan, A. Eberhardt, Z. Tebb, K. Heard, R.F. Wendlandt, and M. Kosnett. J. Emerg. Med., 44(2), 367-372, (2013).

28. D. Salazar. Estudios Atacameños, 36, 43-72, (2008).

29. Sepúlveda, M., S. Gutierrez, M. Campos-Vallette, E. Clavijo, P. Walter, and J.J. Carcamo. J. Chil. Chem. Soc., 58(3), 1651-1653, (2013).

30. M. Sepúlveda, D. Valenzuela, L. Cornejo, H. Linqueo, and H. Rousselière. Chungara, 45(1), 143-159, (2013).

31. S. Byrne, D. Amarasiriwardena, B. Bandak, L. Bartkus, J. Kane, J. Jones, J. Yañez, B. Arriaza, and L. Cornejo. Microchem. J., 94, 28-35, (2010).

32. B.T. Arriaza, L. Cornejo, H. Lienqueo, V.G. Standen, C.M. Santoro, N. Guerra, J. Van Hoesen, and M. Santos. Chungara, 44(1), 177-194, (2012).

33. R. Berton. Annals of medicine cinnabar. The New Yorker, December 8 , 94-102 (1986).

34. B. Arriaza, and L. Pfister. Working with the Dead. Human Remains. Guide for Museums and Academic Institutions. Edited by Vicki Cassman, Nancy Odegaard, and Joseph Powell. AltaMira Press, United States. Pp. 205-221 (2006).

35. L. Figueroa. Arica Inserta en una Región Arsenical: El Arsénico en el Ambiente que afecta y 45 siglos de Arsenicismo Crónico. Arica, Chile: Universidad de Tarapacá (2001) 